\title{
Sustainability in civil construction applied in the construction site phase
}

\author{
E. Vazquez ${ }^{1}$, S. Rola ${ }^{2}$, D. Martins ${ }^{1}$, M. Freitas ${ }^{3}$ \\ \& L. Pinguelli Rosa ${ }^{3}$ \\ ${ }^{I}$ Department of Civil Construction, Federal University of Rio de Janeiro, \\ UFRJ, Brazil \\ ${ }^{2}$ Department of Architecture and Urbanism, Federal Rural University of \\ Rio de Janeiro, UFRRJ, Brazil \\ ${ }^{3}$ Post-Graduation Program on the Energy Planning, Federal University \\ of Rio de Janeiro, COPPE/UFRJ, Brazil
}

\begin{abstract}
This paper presents an analysis of the theme of sustainability applied to the construction site, showing some impacts that may be imposed on the environment during the construction phase of a building and presenting some solutions to alleviate these effects. World history shows us that buildings have always been constructed to meet the immediate and basic needs of humankind. At this time of rapid growth, scant care has been taken about construction techniques or environmental conservation. Indeed, increased environmental degradation has resulted in serious risks to society and, bearing in mind that over $60 \%$ of the solid waste generated in urban centers is from construction sites, the need arises to develop techniques and solutions to mitigate these impacts. This paper seeks to present a research study and diagnosis at the construction site stage into the process of sustainability of an undertaking, with the completion of a case study. The article is structured in four parts: presentation of a brief introduction to the topic and the research methodology to be used; description of certification processes for civil construction; description of risks and mitigation of same at the construction site phase; and a case study focusing on sustainability during the construction phase of an undertaking. A sustainable undertaking is defined not only by environmental and social benefits in its use and operation, but also in its construction. This phase can cause serious damage and impacts to the neighborhood and the environment, such as depletion with excessive
\end{abstract}


consumption or wastage of natural resources and increased pollution caused by poor management of the construction site.

Keywords: sustainability, construction, management, construction site, environment.

\section{Introduction}

Modern industry coupled with technology has transformed humankind, and the consequences of the new mentality, which was heralded in with the Industrial Revolution, were felt during the twentieth and the early twenty-first centuries. They are characterized by the association of the concept of development with the increased use and consumption of the soil, as well as sources of energy and natural resources in general, and led to the formation of metropolitan agglomerations. These concentrations over time gave rise to strong environmental degradation processes Duarte [1].

World history shows us that civil construction has always existed to meet the basic and immediate needs of humankind, and at this time of rapid growth, scant attention has been given to construction techniques and environmental conservation.

There is now a pressing need to take steps to reduce or neutralize this environmental degradation. In the construction area, technical aspects that favor the construction of buildings that meet this requirement, now commonly referred to as "environmentally correct or sustainable buildings", are beginning to emerge.

Given the increase in environmental degradation, resulting in serious risks to society in general, and bearing in mind that over $60 \%$ of solid waste generated in urban centers comes from construction sites, according to Credídio [2], the need arises to develop techniques and solutions to mitigate these impacts.

Sustainable buildings have been the subject of much recent debate. This project aims to focus on sustainability during the construction phase of an undertaking. This phase has not been given the necessary attention, though it is of fundamental importance for environmental preservation. A sustainable undertaking is defined not only by the environmental and social benefits in its use and operation, but also in its construction.

\section{Methodology}

The theme under scrutiny was developed through an exploratory field study of the environmental impacts generated by the construction site, with the presentation of some interventions to minimize these impacts by integrating the concepts of sustainable construction. Preparation of the article was based on bibliographical research, interviews with market professionals, published articles, thereby creating a comparative study of efficient solutions for a sustainable construction site. 


\section{Sustainability in civil construction - certifications}

Based on the current world scenario regarding the protection of the environment there has also been an increased demand to implement sustainable methods in the civil construction sector. This has led to a large increase in sustainable buildings around the world, including Brazil.

Sustainable construction is concerned with the rational use of natural resources, as the civil construction industry is one of the human activities that most impact the environment. It is responsible for $40 \%$ of the consumption of natural resources, $34 \%$ of water consumption and $55 \%$ of wood consumption. There is also concern about the waste generated by the constructions, which is then discarded in inappropriate areas, thereby polluting the cities. No less than $67 \%$ of the total mass of solid urban waste comes from construction sites Credídio [2].

When the project for an undertaking has sustainable strategies, such that the whole cycle of the project has been planned to cause the minimum possible environmental impact, an environmental certification through some processes can be obtained.

The 'green building' certifications in developed countries concentrate on different aspects of the construction. Brazil has followed the footsteps of the United States, which foster the rationalization of resources with savings in water and energy. In this aspect, the Brazilian Committee for Sustainable Construction (CBCS) was recently established. It is a non-profit civil association that seeks to contribute to the promotion of sustainable development through the generation and dissemination of knowledge and the mobilization of the productive chain of civil construction and its customers and consumers.

\section{Risks and mitigations at the construction site stage}

The construction phase gives continuity to what was conceived and projected at the earlier stage. Many companies have not devoted sufficient attention to the interference caused by construction sites, which also have significant impacts, such as inconveniences to the neighborhood (noise, visual, etc.), pollution (soil, water and air), impacts of the construction site (on ecosystems, erosion, siltation, traffic, etc.) and the consumption of resources (mainly water and energy).

These interferences caused by the construction site affect society at the local level, including workers, neighborhoods and ecosystems, and at a global level, affecting society as a whole, especially in relation to pollution Cardoso and Araújo [3].

\subsection{Impacts generated by the construction site}

When defining the standard of the building to be constructed, a program of requirements is prepared and, based on the definition of the scope, it is possible to identify the potential risks of environmental impacts. Once the risks have been identified, it is possible to plan alternatives that address the mitigation actions for them, seeking interventions in order to attempt to increase their social and 
Table 1: $\quad$ Potential environmental impacts during the construction phase.

\begin{tabular}{|c|c|}
\hline Removal of buildings & $\begin{array}{c}\text { Generation of a large volume of waste when the structure is of } \\
\text { reinforced concrete with mortar finishing. }\end{array}$ \\
\hline $\begin{array}{c}\text { Suppression of the } \\
\text { vegetation and erosion }\end{array}$ & $\begin{array}{c}\text { Generation of a dynamic process of change in the local ecosystem, } \\
\text { bringing risks to fauna and flora. It also causes the exposure of the } \\
\text { lower strata that in general, are more susceptible to erosion. }\end{array}$ \\
\hline $\begin{array}{c}\text { Temporary } \\
\text { constructions }\end{array}$ & $\begin{array}{c}\text { Health risks, due to precarious conditions of hygiene, and worker } \\
\text { safety, due to potential accidents. }\end{array}$ \\
\hline $\begin{array}{c}\text { Storage and handling } \\
\text { of materials }\end{array}$ & $\begin{array}{c}\text { Chemical contamination of the soil due to incorrect storage and } \\
\text { handling of materials. }\end{array}$ \\
\hline $\begin{array}{c}\text { Circulation and } \\
\text { maintenance of } \\
\text { equipment }\end{array}$ & $\begin{array}{c}\text { Impacts of deterioration of air quality; noise pollution, inconveniences } \\
\text { to the community, alterations in security conditions in the } \\
\text { neighborhood. }\end{array}$ \\
\hline $\begin{array}{c}\text { Consumption and } \\
\text { wastage of resources }\end{array}$ & $\begin{array}{c}\text { Accelerated depletion of mineral deposits and natural resources. } \\
\text { Generation of waste }\end{array}$ \\
\hline Air quality & High cost and increase in volumes sent to discarding areas. \\
& $\begin{array}{c}\text { Non-renewal of air directly impacts the health of the worker, causing } \\
\text { discomfort, damage to health, drowsiness, and loss of reaction } \\
\text { capacity, asphyxia, or even death. }\end{array}$ \\
\hline
\end{tabular}

environmental performance without generating high costs in the implementation phase. Table 1 describes some environmental impacts that may occur during the construction phase. Lima and Lima [4].

\section{Case study: sustainable construction sites}

The case study deals with the interventions that were made in the implementation of the construction site of a hospital, in order to obtain a building site with a reduced environmental impact. This study describes the environmental impacts caused by the construction site and the strategies employed to mitigate these effects, in accordance with the concepts of sustainability required for LEED certification [5]: sustainability of the workspace; energy efficiency; rationalization of water use; sustainability of materials; and internal environmental quality at the construction site.

With regard to sustainability requirements that were established for the construction site, there are items such as: the control of erosion and sedimentation; reduction of water consumption; solid waste generated during construction; internal air quality; and the use of certified and low toxicity recycled materials. The items used at this stage also add points to the items used in the final undertaking, accumulating points and contributing to a higher level of certification.

\subsection{Description of the sustainability parameters}

\subsubsection{Sustainable space}

Relating to the first item, Table 2 shows the major impacts caused by the construction site, and the intervention that was performed.

This environmental impact is considered a pre-requisite for the Sustainable Space category. This item establishes the implementation of an Erosion and Sedimentation Control Plan and the adopted strategies of which are described hereafter. 
Table 2: Impacts and interventions at the construction site.

\begin{tabular}{|l|c|c|}
\hline $\begin{array}{l}\text { Sustainable } \\
\text { Space (SS) }\end{array}$ & Impacts on the surrounding area & Intervention \\
\cline { 2 - 3 } & Erosion and Sedimentation & $\begin{array}{c}\text { Protected embankments and reduction } \\
\text { of sediments in the air }\end{array}$ \\
\hline
\end{tabular}

The building has a basement, and due to the size of the plot of land it was decided to conduct the excavation for the building with embankments around the entire work area. To prevent soil erosion of the embankments and the washing away of soil during heavy rains, the use of plastic screens was adopted for their protection, as can be seen in Figure 1.

For the control of sedimentation, the construction site is regularly irrigated with water from the lowering of the water sheet. As the construction site is constantly humidified, the movement of cars inside the construction site does not generate dust.

For any sweeping in the construction site, the area is first irrigated, or else rainwater is used (for cleaning the area outside the undertaking, in this case), as can be seen in Figure 2.

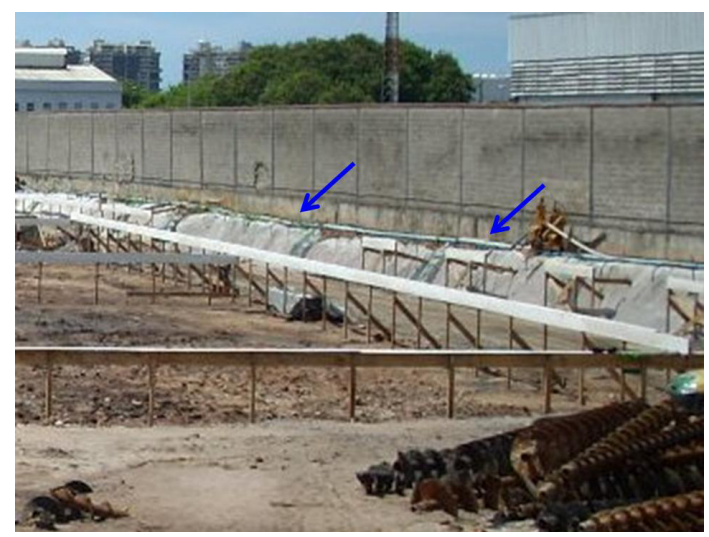

Figure 1: Embankments protected with screens to avoid erosion.
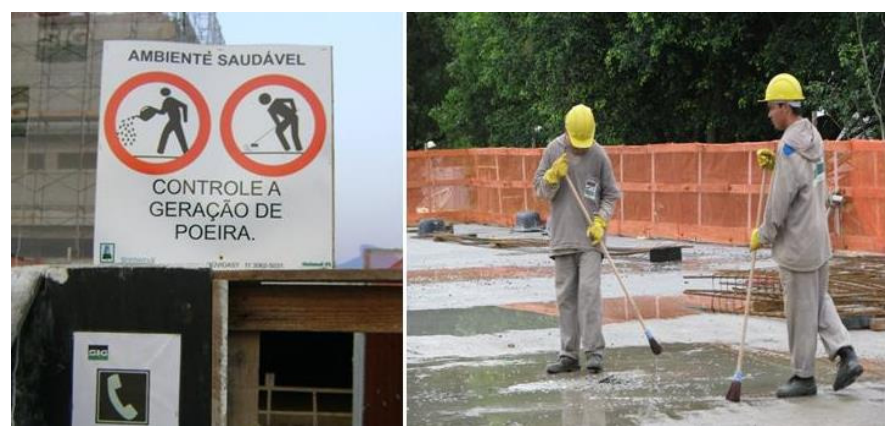

Figure 2: Control of sedimentation and sweeping of the construction site using rainwater and avoiding the generation of dust. 


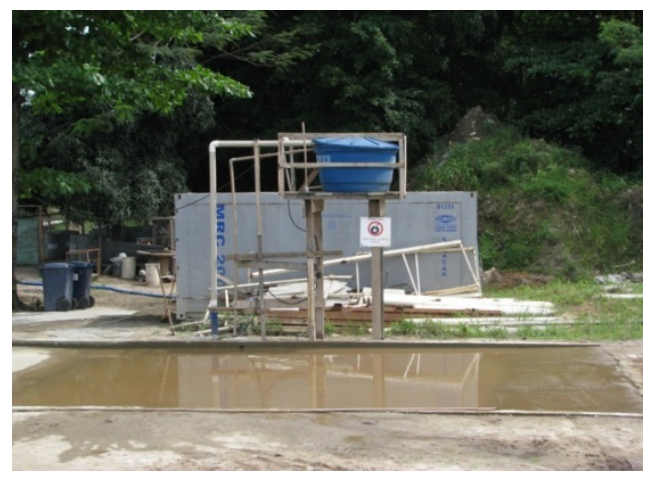

Figure 3: View of the wheel-washers.

The trucks filled with waste leaving the site are enclosed with canvas to avoid the suspension of sediments on the journey to the external environment. Another measure to prevent the trucks from fouling the streets around the building and raising dust while circulating, was to deploy a system for washing wheels, as shown in Figure 3.

\subsubsection{Water efficiency}

In relation to the consumption and loss of water, Table 3 shows the impact and intervention which was performed at the construction site.

Table 3: $\quad$ Impacts and interventions at the construction site.

\begin{tabular}{|l|c|c|}
\hline \multirow{2}{*}{ Rational Water Use (WE) } & Impacts & Intervention \\
\cline { 2 - 3 } & Wastage of drinking water & $\begin{array}{c}\text { Reduced consumption of } \\
\text { drinking water by recycling }\end{array}$ \\
\hline
\end{tabular}

In this category, version 2.1 of the LEED certification does not establish any requisites regarding water consumption. Credits are based on use and occupancy of the undertaking and there are no references to the construction site. However, in a sustainable construction site, the wastage of water is also considered a crucial impact on the environment.

Therefore, in order to reduce water consumption and avoid wastage, a system to capture water from the water sheet was adopted. This water is used for routine purposes on the construction site, such as the toilet flushes (Figure 4), washing sidewalks and cleaning work, thereby avoiding the purchase from water supply trucks or the local water utility provider. To disseminate this concept, lectures are staged regularly to promote the sustainability of the construction site and a reduction in water consumption and wastage. 


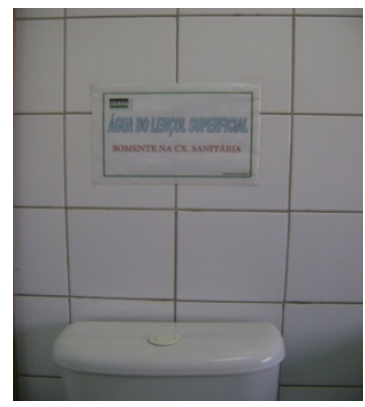

Figure 4: $\quad$ Notice regarding the use of recycled water in the bathrooms.

\subsubsection{Energy and atmosphere}

Regarding this item, Table 4 highlights the main impacts caused by the construction site, and the intervention that was performed.

Table 4: $\quad$ Impacts and interventions at the construction site.

\begin{tabular}{|c|c|c|}
\hline \multirow{2}{*}{$\begin{array}{c}\text { Energy and Atmosphere } \\
(\text { EA) }\end{array}$} & Impacts & Intervention \\
\cline { 2 - 3 } & Wastage of energy & $\begin{array}{c}\text { Reduction in consumption of energy } \\
\text { with more open environments }\end{array}$ \\
\hline
\end{tabular}

Reducing energy consumption is treated in this category as the second requisite. However, this item does not score points for reduction performed at the construction site. But, as in the former category, wasting energy on a sustainable construction site is not permitted.

This being the case, the construction site office was designed with many windows to take maximum advantage of natural lighting and ventilation, as seen in Figure 5. There is also a ventilation area between the ceiling and the roof, thereby reducing heat absorption through the roof. The electrical installation project included independent circuits, ensuring that lights are not left on in empty environments. Compact fluorescent lamps were used in all internal areas of the offices and halls of the construction site. Lectures, educational campaigns and dissemination of this concept were also offered to all employees.

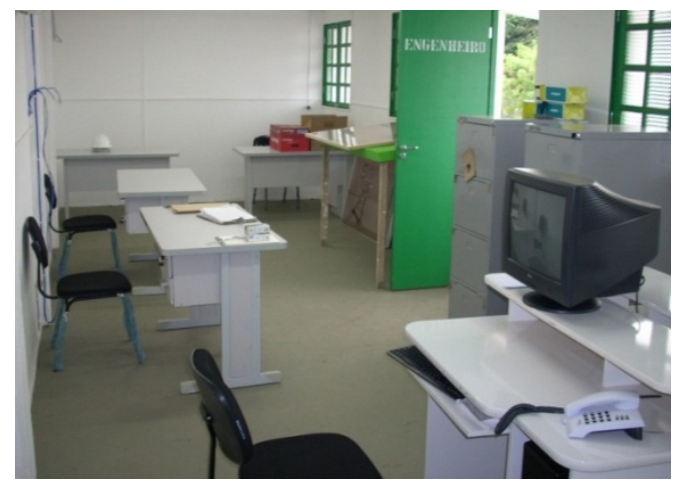

Figure 5: Engineers' office on the construction site with many windows. 


\subsubsection{Consumption of materials and the generation of waste}

Regarding the consumption of materials and solid waste generation, Table 5 highlights the main impacts and the intervention that was performed.

This category includes purchase of materials, generation and management of waste. The storage and collection of recyclable waste is the only requisite. This item is not applied to the construction site, but is addressed in certification credit 2, which refers to management of waste from construction. Credits 4.1 and 4.2, concerning the use of materials with recycled content, 5.1 and 5.2, concerning the use of regional materials, 6 and 7 relating to the use of rapidly renewable materials and certified wood, respectively, are each equivalent to 1 point in the LEED certification. The treatment given to these items is described below.

Table 5: Impacts and interventions at the construction site.

\begin{tabular}{|c|c|c|}
\hline & Impacts & Intervention \\
\cline { 2 - 3 } Materials and & Generation of solid waste & Waste management \\
Resources (MR) & Saturation of sanitary & Recycling of materials \\
& landfills & Using recyclable and regional materials \\
& $\begin{array}{c}\text { Pollution from waste and } \\
\text { transportation }\end{array}$ & \\
\hline
\end{tabular}

The waste generated on the construction site is grouped separately according to its characteristics, and is then sold for recycling. Training sessions are also staged explaining the correct use of each material in order to avoid wastage. Some of the materials that are recycled, such as scrap iron and wood, are separated and identified in certain locations around the construction site, and subsequently sold to agencies and companies that recycle (Figure 6).

Designated areas for smaller waste such as plastics and packaging of paints, separated in accordance with CONAMA resolution No. 307/2002 were also created. This material is then bundled and sold for recycling. Organic waste, like leftover food, is deposited in separate buckets, for collection by a company specializing in the treatment of organic waste.

Regarding to the consumption of materials, preference is given to companies that work with recycled materials and companies that are within a radius of approximately 500 miles from the construction site. This benefits the local economy and ensures that carbon dioxide emissions and the consumption of fuel used in freight delivery are also reduced.

The credit for the use of certified wood is not applicable to the wood used during construction, only for wood in the building, such as furniture and wooden structures. In this undertaking some wooden furniture will be used, and the wood used will have to have FSC (Forest Stewardship Council) certification, represented in Brazil by the 'Conselho Brasileiro de Manejo Florestal - FSC Brasil,' with the guarantee that it is from reforested areas.

Although this does not count toward the certification credit score, the moulds used in the construction have reforestation certificates, and the company contracted to provide this service has an environmental support program. The moulds that arrive at the construction site are already cut and adapted to perform the services and have a thin finishing film. In addition to the project for 


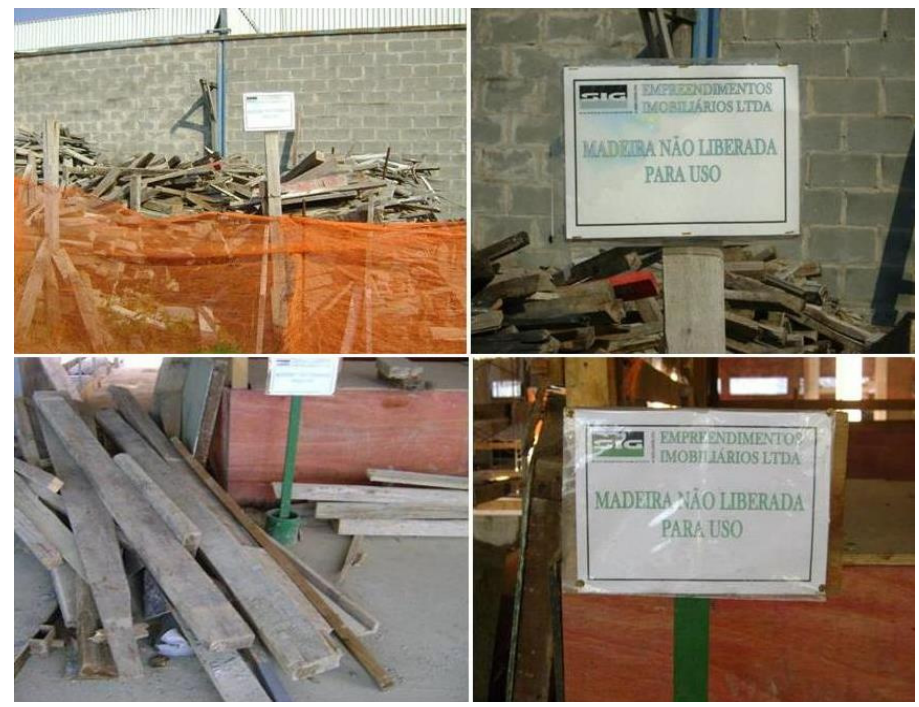

Figure 6: Wood separated for subsequent recycling processes.

rationalization of the construction of the moulds, this resulted in their extended use during the works and less waste.

All the steel purchased for the construction, of the AC-50 and AC-25 categories has about $70 \%$ to $85 \%$ of manufacturing components of recyclable origin.

The cement used was PC and PC-II-III, which is composed of waste such as granulated slag from blast furnaces and pozzolanic materials, resulting in lower consumption of clinker and therefore less $\mathrm{CO}_{2}$ emissions and preservation of the deposits.

When purchasing the aluminum for the construction site, aluminum manufactured using green billet is selected, as it is composed of more than $80 \%$ of recycled raw materials.

All materials that have recycled products in their composition are accompanied by a declaration in which the supplier of the material states the percentage of recycled components in each material.

Other measures also adopted to reduce wastage include the dissemination of the specifications for the preparation of mortar to be used in the construction site on all floors and the use of plastic-based ingredients. Use of the latter reduces wastage because it has a smoother surface than concrete, and mortar made is $100 \%$ usable.

\subsubsection{Internal environmental quality}

Regarding this item, Table 6 presents the main impacts and the interventions made.

The requisites of this category refer to minimum air quality performance and the control of smoke generated by tobacco smoking. These two items are evaluated when the building is already in use, and are not applicable to the 
Table 6: Impacts and interventions at the construction site.

\begin{tabular}{|c|c|c|}
\hline \multirow{2}{*}{$\begin{array}{c}\text { Internal environmental } \\
\text { quality (EQ) }\end{array}$} & Impacts & Intervention \\
\cline { 2 - 3 } & Air pollution & $\begin{array}{c}\text { Reduction in carbon emissions } \\
\text { and the production of sediment }\end{array}$ \\
\hline
\end{tabular}

construction site. However, they are addressed in certification credit 3, which refers to air quality during the execution of the works and stipulates the creation of an Air Quality Management Plan. Credits 4.1, 4.2 and 4.3 relate to the use of materials with low VOC. Each item is worth one point in the system.

To ensure the best air quality at the construction site, an Air Quality Management Plan was created. This plan envisages no air pollution or materials that can release this pollutant waste in the future, with some measures that are already being implemented at the construction site and other measures that will be implemented throughout the course of performance of the services, as described below.

For the cleaning procedure adopted during construction, as stated above the irrigation of surfaces to be cleaned is adopted, followed by sweeping of the indoor environments, with manual collection of larger debris.

To ensure the health of workers, smoking is not permitted on the construction site. For this purpose, a space was created for those who smoke known as the smoking area (Figure 7), a restricted and well ventilated area in the construction site.

The sequence of installation of materials is planned in order to avoid contamination of porous materials such as insulation, carpeting, ceilings and plasterboard, so that they do not disperse this pollution in the future. The storage of these materials must be protected with plastic preventing them from being contaminated.

The thermo-acoustic insulation surfaces will only be installed when all services that may release VOCs or dusts are concluded, thereby preventing damage to the materials. However, some of these materials need to be installed inside walls, as in the case of the fiberglass insulation that will be used in the drywalls. For this material, proper storage is required before execution, and at

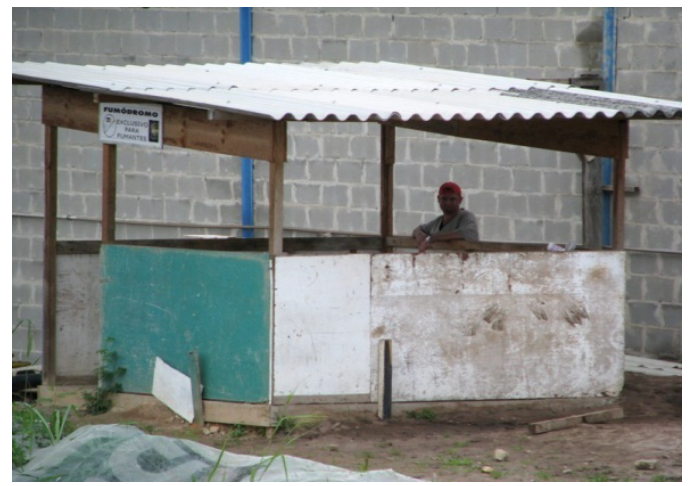

Figure 7: $\quad$ Smoking area. 
the moment of installation this will be done in such a way as not to expose the materials to exposure to odors.

All products that can emit VOCs or odors are sealed and properly stored in ventilated areas or sheltered from light and in their original containers to avoid leakage and consequent contamination of the environment. The furniture and carpeting will be adequately protected with plastic after its installation.

The system designed to meet the internal thermal requirements generated by the functions to be performed in the location will only come into operation when all the construction services are considered to be completed, including any final touches and rectifications due to flaws in execution. Before use, all air intakes as well as vents and diffusers will be protected by plastic sheeting that will serve as a sealant, preventing the entry of particulate matter and thereby reducing the effectiveness of the filtering elements. Furthermore, when the works are completed the ducts will be inspected and cleaned to minimize contamination

In the event that the installed fan coils need to be used during construction, temporary filters will be installed in addition to the existing filters in places where exposure to dust occurs, though all filtering elements will be replaced at the end of the works. In this case, the sites adjacent to where the works are in progress will be isolated from contamination by filters installed inside the ducts. These filters will ensure that the air conduits are kept clear.

In places where there is the need to perform heavy works that generate large amounts of dust, while the adjacent spaces remain operational, and the filtering system installed is not effective, this may be increased by using Activated Carbon or Potassium Permanganate. Building materials may not be stored in the places where the machines will be located.

To prevent the accumulation of debris and particulate materials in suspension, both the air conditioning system diffusers and the ventilation duct inlets and windows will be sealed with plastic sheeting until the completion of construction services, including any final touches and rectifications due to flaws in execution. All environments, as they are completed, will have their access doors sealed with temporary sealant in the cracks, or plastic sheeting to protect places that have no doors.

The priority in the use of construction equipment is given to those with the least impact on the premises where construction-related activities are not being performed.

\section{Final considerations}

With growing worldwide concern regarding the preservation of the environment, there has been a considerable amount of well-documented input from lectures and discussions by countries and organizations, which propose some guidelines to ensure sustainable development.

The civil construction industry contributes significantly to the modification of the physical space in which we live, and can radically alter the climate and produce waste and sediment that have a crucial impact on the environment. For this reason, there is a pressing need to develop strategies that mitigate or nullify these impacts. 
The quest for sustainable construction has resulted in the certification of some undertakings around the world. In Brazil, the adoption of sustainable strategies is gradually being absorbed by the entrepreneurs.

As seen in this paper, the construction phase of an undertaking is responsible for the bulk of the environmental impacts. The construction site deserves special attention and all possible damage that may be generated by the construction site during construction should be carefully monitored in order to analyze what can be avoided. In urban areas, where the highest concentration of civil construction occurs, care must be taken to preserve the existing ecological environment, to avoid sudden climate change, and to curb the pollution generated, which degrades the environment and damages the neighborhood.

When all the impacts that may be caused by the construction site have been assessed, the entrepreneur must prioritize them to determine which of these impacts will be addressed and to what extent. Once that has been established, the necessary technologies and actions of a managerial nature required can be defined, establishing the resources that need to be implemented, such as equipment to be bought, professionals to be trained or hired, managerial tools to be implemented, etc, and the timeframes and costs involved.

The civil construction industry still has a long way to go on the issue of sustainability, though positive results in reducing environmental degradation and the savings generated in the consumption of resources has been a driving force behind these changes. New technologies that contribute to these reductions are more readily available on the market and with an ever decreasing differentiation in price, resulting in lower costs for a sustainable undertaking. In this case study, the increase in costs of the hospital complex will vary between $6 \%$ and $14 \%$, the greatest impact being the investment in electrical installations and eco-efficient air conditioners.

In light of what has been presented above, it can be seen that, besides achieving the objectives originally proposed, this work can provide a contribution to the study of sustainability within the construction site.

\section{References}

[1] Duarte, Anselmo. "Casa de Alta Tecnologia e Ecologicamente Correta". Virtual Book, 2007. <http://www.crear.com.br/casa_ecologica.php>.

[2] Credídio, Fernando. "Construções sustentáveis: conforto e respeito ao meio ambiente - Parte 1". Virtual Book, 2008. http://www.ifk.org.br/construcoes sustentaveis:_conforto_e_respeito_ao_meio_ambiente_parte_1_344.html $>$.

[3] Cardosa, Francisco Ferreira, ARAUJO, Viviane Miranda. "Levantamento do estado da Arte: Canteiro de Obras". Tecnologia para Construção Habitacional mais Sustentável. São Paulo, 2007.

[4] Lima, Rosimeire Suzuki, LIMA, Ruy Reynaldo Rosa. "Guia para Elaboração de Projeto de Gerenciamento de Resíduos da Construção Civil". Série de Publicações temáticas do CREA- PR, nº 1. Paraná, 2009.

[5] LEED, "Leadership in Energy \& Environmental Design - LEED", v.3. USGBC, 2009. 